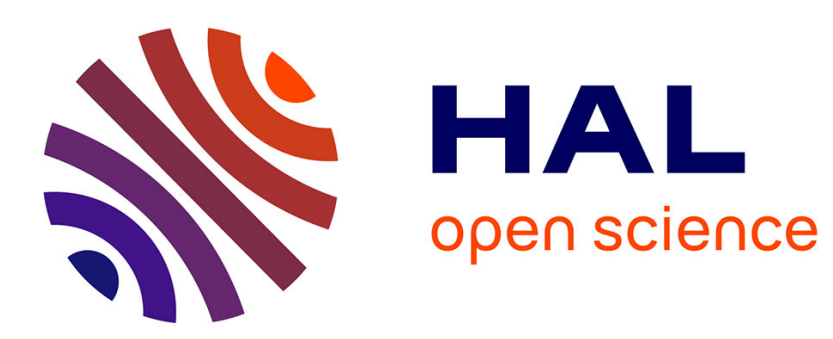

\title{
Helium backscattering from a randomly stepped surface
}

\author{
J. Lapujoulade, Y. Lejay
}

\section{To cite this version:}

J. Lapujoulade, Y. Lejay. Helium backscattering from a randomly stepped surface. Journal de Physique Lettres, 1977, 38 (14), pp.303-306. 10.1051/jphyslet:019770038014030300 . jpa-00231382

\section{HAL Id: jpa-00231382 https://hal.science/jpa-00231382}

Submitted on 1 Jan 1977

HAL is a multi-disciplinary open access archive for the deposit and dissemination of scientific research documents, whether they are published or not. The documents may come from teaching and research institutions in France or abroad, or from public or private research centers.
L'archive ouverte pluridisciplinaire HAL, est destinée au dépôt et à la diffusion de documents scientifiques de niveau recherche, publiés ou non, émanant des établissements d'enseignement et de recherche français ou étrangers, des laboratoires publics ou privés. 


\title{
HELIUM BACKSCATTERING FROM A RANDOMLY STEPPED SURFACE
}

\author{
J. LAPUJOULADE and Y. LEJAY
}

Service de Physique Atomique, Section d'Etudes des Interactions Gaz-Solides, C.E.N. Saclay, B.P. 2, 91190 Gif sur Yvette, France

(Reçu le 27 avril 1977, révisé le 9 juin 1977, accepté le 14 juin 1977)

\begin{abstract}
Résumé. - On a étudié la rétrodiffusion de l'hélium par une surface propre mais géométriquement rugueuse. L'intensité diffusée présente en fonction de l'angle d'incidence une série de minima et de maxima. On montre que ces extrema sont dus à des interférences de Bragg entre les faisceaux d'atomes diffusés par des terrasses séparées par des marches d'une hauteur monoatomique. Les longueurs moyennes des terrasses déduites du profil d'intensité sont en bon accord avec la macrorugosité.
\end{abstract}

Abstract. - The backscattering of helium from a geometrically rough but clean surface has been studied. It is found that the scattering intensity $v s$. incidence angle shows a sequence of minima and maxima. These extrema are shown to be due to Bragg interference between helium atoms scattered by terraces separated by steps of one atom. From the intensity profile mean terrace lengths are deduced which are in a reasonable agreement with the macroroughness.

In previous experimental work on the scattering of helium by (100) copper we have shown that [1] :

1) The specular peak of helium is a coherent elastic peak.

2) Its amplitude depends upon incidence angle, beam energy and crystal temperature through a Debye-Waller factor $2 \mathrm{~W}$.

$$
I / I_{0}=\mathrm{e}^{-2 W}
$$

where $I$ is the specular peak intensity, $I_{0}$ is the incident beam intensity.

$2 W$ may be written as :

$$
2 W=+48 \mu \frac{E_{\mathrm{i}}}{2 k \Theta_{\mathbf{s}_{\mathrm{ap}}}^{2}} T_{\mathrm{s}}\left(\cos ^{2} \theta_{\mathrm{i}}+D / E_{\mathrm{i}}\right)
$$

where :

$\mu:$ mass ratio $=m_{\mathrm{He}} / m_{\mathrm{Cu}}$

$E_{\mathrm{i}}$ : mean energy of the incident atoms

$\theta_{\mathrm{i}}:$ angle of incidence

$D$ : well depth of the helium-metal interaction potential

$T_{\mathrm{s}}$ : crystal temperature

$\Theta_{\mathrm{s}_{\mathrm{app}}}$ : is what we have called an apparent surface Debye temperature. It depends upon the number of crystal atoms which directly interact with the helium atom (four for the (100) face) and upon their mean square and mean correlated displacements. We found $\Theta_{\text {sapp }}=370 \mathrm{~K}$ for the $(100)$ face. This value is discussed in reference [1].

3) In plane diffraction is not observed within our experimental flux sensitivity $\left(0.001 I_{0}\right)$.
In the analysis which has lead to these conclusions we have assumed that the experimental surface was a perfect crystallographic plane. This is an idealized situation since in practice there is certainly a random distribution of steps on the surface. In order to check the influence of these geometrical defects we have done the same experiments on a sample which has been macroscopically roughened.

The experimental set-up is the same as that in the previous work [1, 2, 3]. A very well collimated nozzle beam (Campargue's type [4], aperture $0.25^{\circ}$ ) is scattered by a copper single crystal into an ionization detector (angular resolution $0.25^{\circ}$ ). The incidence angle may be adjusted between 6 and $90^{\circ}$ and the beam energy between 0.06 and $0.25 \mathrm{eV}$. The mean square velocity spread of the beam is $1.5 \times 10^{-3}$. We are able to make both flux and velocity measurements by a time-of-flight technique. Only in plane measurements are possible.

The crystal ((100) face) is first made free from sulphur by heating in a hydrogen furnace. In the work reported here before the sample is placed in the experimental chamber it is roughened by an electrochemical process. The resulting surface (as measured by light interferometry) is randomly corrugated, the mean corrugation amplitude is about $0.3 \mu$, and the mean corrugation wave length about $10 \mu$. It is quite reasonable to assume that these corrugations are built, at the atomic scale, from (100) terraces separated by steps of one atomic plane height. From the slope of the corrugation a mean step separation of about 10 unit mesh is to be expected. 
The surface is thus cleaned in situ by ion bombardment $\left(\mathrm{Ar}^{+}, 400 \mathrm{~V}, 10 \mu \mathrm{A}, 1\right.$ hour $)$ and annealing (773 K, $15 \mathrm{~min}$.). The cleanliness is checked in situ by a cylindrical mirror Auger spectrometer. The surface was put in to the interferometer microscope before and after the scattering experiment. This shows us that the corrugation was practically not affected by the cleaning procedure.

The sample was also observed in a separate LEED experiment. It displays the characteristic pattern of the (100) face with bright sharp spots. We did not make any attempt to measure the intensity $v s$. energy profile of these spots.

In figure 1 we have plotted the variation of the specular intensity as a function of the incidence angle for various beam energies. For the sake of comparison the curves for a smooth surface deduced from the previous experiments by [1] and [2] are also plotted. There is a striking difference between these curves :

- The curves related to the corrugated surface are shifted towards lower intensity values.

- They show large minima and maxima.

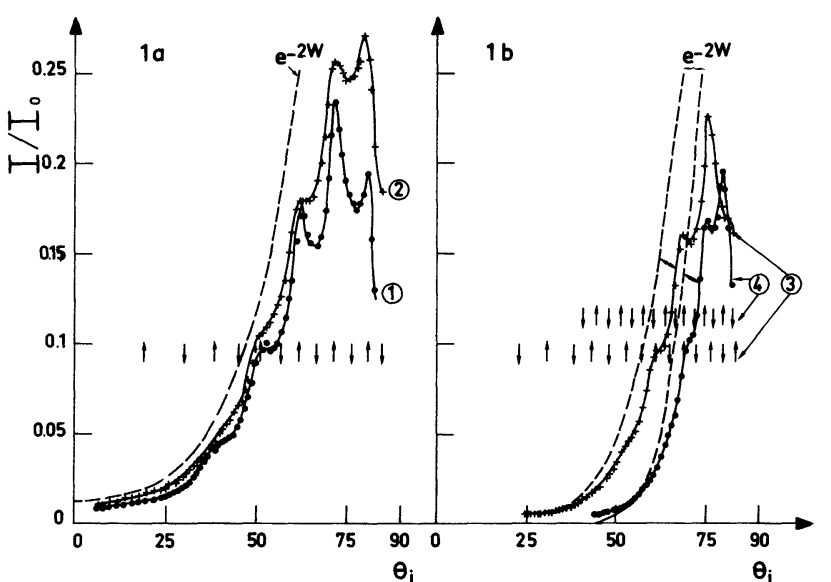

FIG. 1. - Plot of the intensity ratio $I / I_{0} v s$. incidence angle $\theta_{\mathrm{i}}$. Crystal temperature : $473 \mathrm{~K}$. a) Curve 1 , beam energy $=0.063 \mathrm{eV}$; curve 2 , beam energy $=0.063 \mathrm{eV}$ after annealing at $1200 \mathrm{~K}$. b) Curve 3, beam energy $=0.105 \mathrm{eV}$; curve 4 , beam energy $=$ $0.195 \mathrm{eV}$. The positions of Bragg minima and maxima are indicated by arrows.

An attempt to smooth the surface in situ by annealing for 1 hour at $1200 \mathrm{~K}$ was made. The result (curve 2 on figure 1a) is a decrease of the shift and a decrease of the maxima to minima amplitude.

These features strongly suggest that interference between the helium atoms scattered from the various (100) terraces readily occurs. The mechanism is easy to understand using the very simple hard wall model as shown in figure 2 . The helium metal potential in the normal direction is an infinite repulsive hard wall combined with an attractive well (depth $D$ range $a$ ). Along the surface the wall is plane except in the vicinity of steps. Neglecting the wall corrugation between steps is justified by the absence of diffraction on the (100) face.
20

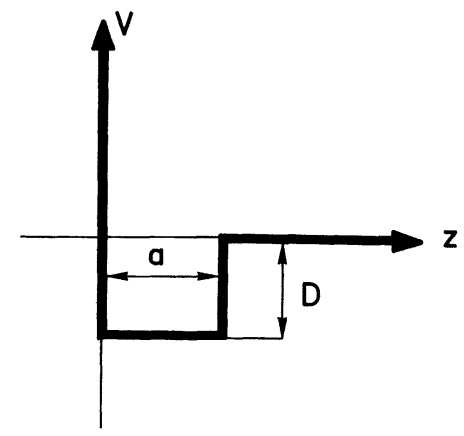

$2 b$

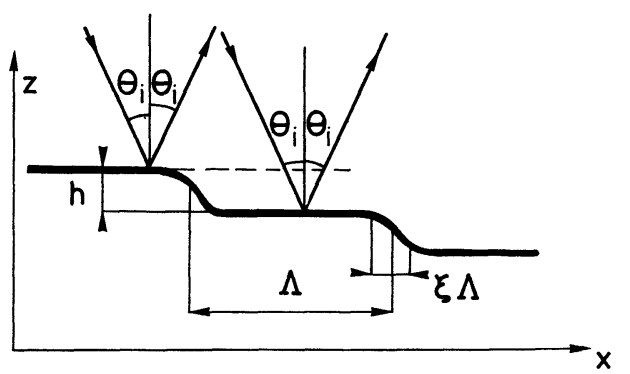

FIG. 2. - Hard-wall model for the surface. a) Hard-wall potential $V(z)$. b) Shape of the hard-wall along the surface.

Thus two helium atoms which strikes two adjacent terraces may interfere according to the usual Bragg condition. Minima will appear when :

$$
2 h \cos \theta_{i}=(n+1 / 2) \lambda
$$

\section{$h:$ height of a step}

$\lambda$ : wave length of the helium beam.

It is not necessary to take into account here the effect of refraction in the potential well provided that the terrace length is large with respect to the potential well range. If $h$ is assumed to be the distance between two (100) planes of copper $(h=1.80 \AA)$ then the position of Bragg minima and maxima are indicated on figure 1 by arrows. The agreement with the experimental positions is quite good.

A better comparison between the calculation and the experiment is achieved when the quantity $\left(I / I_{0}\right) \mathrm{e}^{2 W}$ is plotted instead of $\left(I / I_{0}\right)$. This is done on figure 3 for the lower energy experiment. For $\theta_{i}$ ranging from $35^{\circ}$ to $75^{\circ}$ the position of the extrema agrees with the calculation within experimental accuracy. Below 350 the signal is very low and the signal to noise ratio becomes very bad so that the accuracy of the measurement is poor.

In order to give a more quantitative description of the experimental results we have to make some assumption about the step distribution on the surface. The problem of the scattering of a wave by a randomly stepped surface has been already studied in connection with LEED experiments, particularly by Houston and Park [5], and Cowley and Shuman [6]. The model used by these latter authors is especially suitable for our case. They neglect the influence of steps edge and 


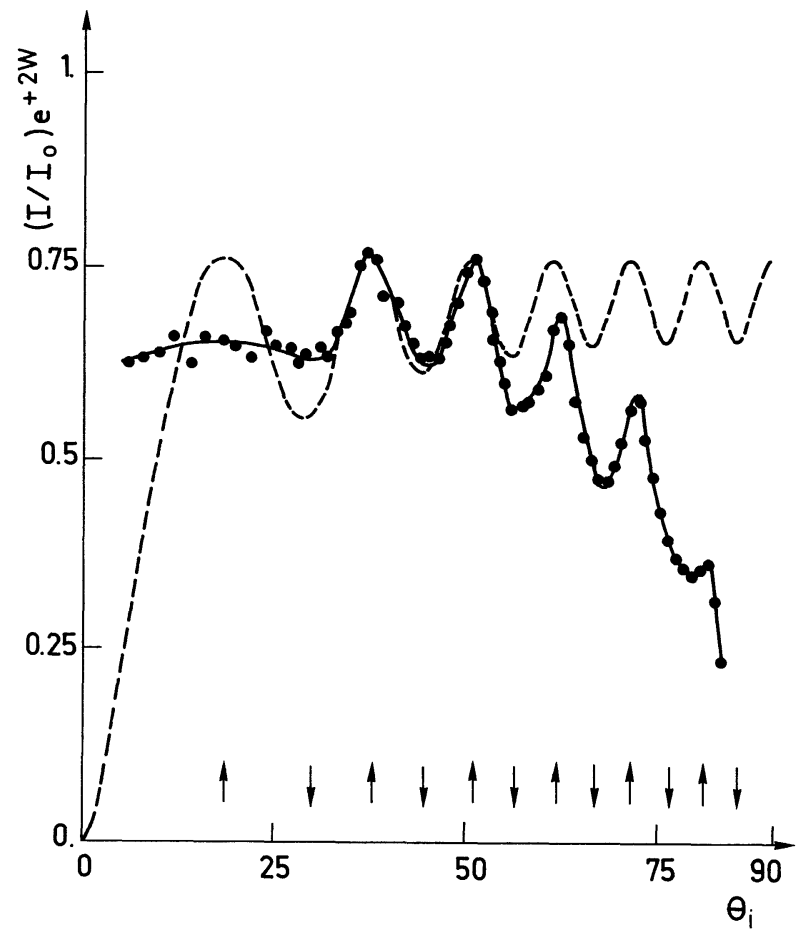

FIG. 3. - Plot of $\left(I / I_{0}\right) \mathrm{e}^{2 \mathrm{~W}} v s . \theta_{\mathrm{i}}$. - Experimental curve; - Calculated curve. The positions of Bragg minima and maxima are indicated by arrows.

they assume that the probability to find $n$ steps between two points at a distance is Poisson distributed :

$$
\left(\frac{|x|}{\Lambda}\right)^{n} \frac{1}{n !} \exp \left(-\frac{|x|}{\Lambda}\right)
$$

where $\Lambda$ is the mean separation of steps. Assuming that this distribution holds in both direction on the surface they get for the scattered intensity

$$
I_{\text {rough }} / I_{\text {smooth }}=\left[\frac{2}{\pi} \operatorname{arctg}\left(\frac{2 \pi \Delta \Lambda}{1-\cos 2 \pi w h}\right)\right]^{2}
$$

where $: h:$ step height

$$
w=2 \cos \theta_{\mathbf{i}} / \lambda
$$

$\Delta:$ reciprocal coherence length of the beam.

For the Bragg maxima equation (4) gives $I_{\text {rough }}=I_{\text {smooth }}$ which is not in agreement with our experimental result. The discrepancy may be ascribed to the atoms which are scattered by step edges. This effect may be roughly taken into account by assuming that around the step edges there is an area where atoms are completely scattered out of the specular direction. Let this area be a fraction $\xi$ of the total sample area then the true intensity ratio must be that given by [4] multiplied by $(1-\xi)$. An exact evaluation of the $\xi$ parameter would involve the knowledge of the exact $\mathrm{He}-\mathrm{Cu}$ potential in the vicinity of the step edges. As this is not known $\xi$ may be regarded as a fitting parameter.
The coherence length of our beam may be evaluated from the formula given by Pendry [7] for electrons :

$$
l_{\mathrm{c}}=\Delta^{-1}=\frac{\lambda}{\left[2 \cos ^{2} \theta_{\mathrm{i}}\left(\overline{\Delta \theta}^{2}\right)+\sin ^{2}\left(\frac{\overline{\Delta E}}{E}\right)^{2}\right]^{1 / 2}}
$$

$\overline{\Delta \theta}^{2}$ mean square angular divergence of the beam $\left(\frac{\overline{\Delta E}}{E}\right)^{2}$ mean square energy spread of the beam. With our beams :

$$
\overline{\Delta \theta}^{2}=3.7 \times 10^{-8} \operatorname{radian}^{2}\left(\frac{\overline{\Delta E}}{E}\right)^{2}=6 \times 10^{-3} \text {. }
$$

Assuming $\xi=0.23$ and $\Lambda=20 \AA$ we calculate by (4) and (5) the curve shown in figure 3 which at least between 30 and $55^{\circ}$ agrees quite well with our experimental curve. This terrace width corresponds to 8 unit mesh in agreement with the macrogeometric estimation above.

If the terraces all had the same width they would form a regular array from which diffraction effects would appear. Indeed diffraction from a regular array of steps has been reported $[8,9]$. But in the present case we checked that they were actually not present which is a good proof of the randomness hypothesis.

From the value of $\xi$ we can estimate that the length along the surface where the potential is perturbed by a step is of the order of 2 unit mesh. This value is quite reasonable since the diameter of the helium atom is of the same order as that of the unit mesh.

This model also explains two observed trends :

1) When the beam energy is raised, $\lambda$ decreases, so that the coherence length also decreases and the ratio $I_{\text {rough }} / I_{\text {smooth }}$ becomes smaller in agreement with the experimental result.

2) The annealing of the sample has certainly reduced the macrogeometric corrugation and consequently increased the mean step distance $\Lambda$. An increase in $\Lambda$ should result in a decrease of both $\xi$ and $I_{\text {rough }} / I_{\text {smooth }}$. So the resulting curve is shifted towards higher $I / I_{0}$ values and modulation by interference smaller, as shown experimentally.

The decrease of the curve which is observed above $50^{\circ}$ is not explained by this model. It may come from two different reasons :

1) For large incident angles the sample does not intercept the whole beam. If the geometry of the beam apparatus was ideal the onset of this effect would be $82^{\circ}$. In fact there are many imperfections (collimator misalignment, displacement of the sample rotation axis with respect to the scattering surfaces) which may contribute to lower this value.

2) It is reasonable to think that the fraction $\xi$ of the beam which is scattered by the steps may be an increasing function of the incidence angle. 
These two effects add with each other so that they are difficult to be taken into account in a realistic calculation.

Nevertheless these first results clearly show that the helium beam scattering technique is a powerful tool to study the atomic structure of surfaces. Compared to LEED it has the advantage that the results are not obscured by dynamical effects and beam penetration. But in order to achieve this purpose correctly we emphasize the importance of the coherence length of the beam i.e. the necessity to work with a very mono- energetic and very well collimated beam. With our beam it seems readily possible to detect atomic steps which are separated by 50 unit meshes.

Acknowledgments. - We are very indebted to Dr. Hoinkes (Physikalisches Institut der Universität, Erlangen) who has suggested to us the possibility of Bragg interference in atomic beam scattering. We thank also Drs. Armand, Degras, Riwan for many valuable discussions and Dr. Manus for his interest in this work.

\section{References}

[1] Armand, G., Lapujoulade, J., Lejay, Y., J. Physique Lett. 37 (1976) L-187.

[2] Lejay, Y., Lapujoulade, J., Armand, G., Rev. Phys. Appl. 8 (1973) 207.

[3] Lapujoulade, J., Lejay, Y., J. Chem. Phys. 63 (1975) 1389.

[4] Campargue, R., Lebehot, A., Rarefied Gas Dynamics, M. Becker, M. Fieberg Editors (DFVLR Press, Porz Wahn RFA) 1974, p. C11.
[5] Houston, J. E., Park, R. L., Surf. Sci. 26 (1971) 269.

[6] Cowley, J. M., Shuman, H., Surf. Sci. 38 (1973) 53.

[7] Pendry, J. B., Low Energy Electron Diffraction (Academic Press, London G.B.) 1974, 6.

[8] Ceyer, S. J., Gale, R. J., Bernasek, S. L., Somorjai, G. A., J. Chem. Phys. 64 (1976) 1934.

[y] Lapujoulade, J., Lejay, Y., to be published. 